\title{
Hommage à Françoise Ozanne-Rivierre
}

\section{(2) OpenEdition \\ Journals}

Édition électronique

URL : http://journals.openedition.org/jso/1120

ISSN : $1760-7256$

\section{Éditeur}

Société des océanistes

Édition imprimée

Date de publication : 1 décembre 2007

Pagination : 351

ISBN : 978-2-85430-010-9

ISSN : 0300-953x

\section{Référence électronique}




\section{Hommage à Françoise Ozanne-Rivierre}

L'équipe « Études océaniennes 》 du LACITOCNRS a la profonde tristesse de vous faire part $\mathrm{du}$ décès de leur collègue et amie Françoise Ozanne-Rivierre, survenu le 11 novembre 2007. Les enseignants de la filière « Langues et Cultures océaniennes" de l'université de Nouvelle-Calédonie, et ses nombreux amis de la Grande Terre et des îles s'associent à notre tristesse.

Ancienne disciple d'André-Georges Haudricourt et de Claude Hagège, Françoise Rivierre est une linguiste internationalement reconnue, pour sa contribution au comparatisme des langues océaniennes, et pour les descriptions qu'elle a publiées de plusieurs langues de NouvelleCalédonie.

Ses principales contributions théoriques portent sur la phonologie historique, le classement génétique des langues kanak et la reconstruction du proto-néo-calédonien. Avec André-Georges Haudricourt, puis avec Jean-Claude Rivierre, elle a contribué à mettre en évidence l'appartenance de ces langues au sous-groupe océanien de la grande famille austronésienne. Avec pas moins de vingt-huit langues réparties en trois sousgroupes différents, la Nouvelle-Calédonie est une aire réputée pour son extrême diversité et sa grande complexité. Depuis les années 1960, Françoise Rivierre a mené des enquêtes de terrain sur plusieurs de ces langues, recueillant une somme impressionnante de documents qui ont été la source et la matière de sa réflexion toute sa vie durant.

Ainsi, après sa thèse, consacrée à une description phonologique et syntaxique du iaai d'Ouvéa (îles Loyauté) en 1976, elle s'est intéressée aux langues de la région de Hienghène, publiant en 1979, avec la collaboration de Poindi Tein, deux volumes de Textes nemi, suivi, en 1982, de l'imposant Dictionnaire thématique des langues de la région de Hienghène rédigé en collaboration avec André-Georges Haudricourt. Elle a poursuivi ce précieux travail de description de langues, en publiant en 1998 le dictionnaire du nyelâyu de Balade, à l'extrême-nord de la Grande Terre, en collaboration avec Baptiste Boiguivie, Scholastique Boiguivie et Éliane Dedane. Enfin, elle venait d'achever la première version d'un dictionnaire thématique des langues pwaamei et pwâpwâ, deux langues du nord de la Grande Terre.

Connue pour sa passion des langues kanak et sa joie de vivre à la tribu, Françoise a toujours eu une conscience aiguë de la nécessité de transmettre et de sauvegarder ces langues souvent menacées.

En bonne disciple d'Haudricourt, elle s'intéressait aussi à la botanique. Ses dictionnaires comportent tous des nomenclatures de la faune et de la flore calédonienne, utiles à la fois pour la compréhension de l'environnement et de la culture kanak, mais aussi pour les reconstructions des termes anciens en linguistique historique.

Depuis 2000, Françoise Rivierre dirigeait l'équipe « Études océaniennes » du LACITO avec le dynamisme, la compétence et les qualités humaines qui l'ont toujours caractérisée. Elle nous laisse le souvenir d'une chercheuse accomplie et passionnée, exigeante mais aussi chaleureuse et généreuse, une personnalité forte et tenace affrontant courageusement toutes les adversités.

Le JSo publiera dans son prochain numéro un hommage retraçant l'œuvre de cette grande chercheuse. 